\title{
Article \\ Coconut Shell-Derived Activated Carbon for High-Performance Solid-State Supercapacitors
}

\author{
Kuan-Ching Lee ${ }^{1}$, Mitchell Shyan Wei Lim ${ }^{1}$, Zhong-Yun Hong ${ }^{2}$, Siewhui Chong ${ }^{1}{ }^{\mathbb{D}}$, Timm Joyce Tiong ${ }^{1}$, \\ Guan-Ting Pan ${ }^{3, * \mathbb{C}}$ and Chao-Ming Huang ${ }^{2, *}$
}

1 Department of Chemical and Environmental Engineering, University of Nottingham Malaysia, Jalan Broga 43500, Malaysia; ebxk11@nottingham.edu.my (K.-C.L.); keby3mli@exmail.nottingham.edu.my (M.S.W.L.); faye.chong@nottingham.edu.my (S.C.); joyce.tiong@nottingham.edu.my (T.J.T.)

2 Green Energy Technology Research Center and Department of Materials Engineering, Kun Shan University, Tainan 710, Taiwan; st112926@gmail.com

3 Department of Chemical Engineering and Biotechnology, National Taipei University of Technology, Taipei 106, Taiwan

* Correspondence: gtpan@ntut.edu.tw (G.-T.P.); charming@mail.ksu.edu.tw (C.-M.H.); Tel.: +886-2-2771-2171-6060 (G.-T.P.); +886-6-2050-359 (C.-M.H.)

check for updates

Citation: Lee, K.-C.; Lim, M.S.W.; Hong, Z.-Y.; Chong, S.; Tiong, T.J.; Pan, G.-T.; Huang, C.-M. Coconut Shell-Derived Activated Carbon for High-Performance Solid-State Supercapacitors. Energies 2021, 14, 4546. https://doi.org/10.3390/ en14154546

Academic Editors: Worapon Kiatkittipong and Jun-Wei Lim

Received: 26 June 2021

Accepted: 23 July 2021

Published: 27 July 2021

Publisher's Note: MDPI stays neutral with regard to jurisdictional claims in published maps and institutional affiliations.

Copyright: (c) 2021 by the authors. Licensee MDPI, Basel, Switzerland. This article is an open access article distributed under the terms and conditions of the Creative Commons Attribution (CC BY) license (https:// creativecommons.org/licenses/by/ $4.0 /)$.

\begin{abstract}
Coconut shells, low-cost and renewable agro-wastes, were used as a starting material in the synthesis of hierarchical activated carbons via hydrothermal, $\mathrm{KOH}$-activation, and carbonization techniques. The ratio of $\mathrm{KOH}$ to hydrochar was varied in a systemic manner to study how it influences the texture and electrochemical behavior of the capacitor. Coconut shell-based carbon coated on nickel foams presented a surface area of $1567 \mathrm{~m}^{2} \mathrm{~g}^{-1}$, with micropores as well as mesopores widely distributed. The sample showed superior electrochemical performance, attaining $449 \mathrm{~F} \mathrm{~g}^{-1}$ at $1 \mathrm{~A} \mathrm{~g}^{-1}$ in $6 \mathrm{M} \mathrm{LiNO}_{3}$ aqueous solution. The solid-state symmetric supercapacitor device delivered a specific capacitance of $88 \mathrm{~F} \mathrm{~g}^{-1}$ at $1 \mathrm{~A} \mathrm{~g}^{-1}$ and a high energy density of $48.9 \mathrm{Whkg}^{-1}$ at a power density of $1 \mathrm{~kW} \mathrm{~kg}^{-1}$. At a wide voltage window of $2.0 \mathrm{~V}$, the sample was highly stable during the cycle test, showing a $92 \%$ capacitance retention at $2 \mathrm{~A} \mathrm{~g}^{-1}$ after cycling for 5000 times. The superior performance is due to the sample possessing great BET surface area, a good distribution of pores, and the usage of a suitable electrolyte. This facilitates an electrical double layer that can be deployed for applications to store energy.
\end{abstract}

Keywords: coconut shell; activated carbon; hydrothermal synthesis; solid state supercapacitor

\section{Introduction}

With greater power densities, as well as being more sustainable compared to secondary batteries, supercapacitors have found wide applications in industrial processes, hybrid electric vehicles, and portable electronics [1,2]. With regards to the charge storage mechanism, supercapacitors generally exist in the form of electrical double-layer capacitances (EDLCs), pseudocapacitors, and hybrid supercapacitors [3]. In general, EDLCs are considered to be promising supercapacitors due to their rapid charge and discharge rate, extended life-cycle, excellent chemical stability, as well as low-cost. Nevertheless, EDLC has unsatisfactory energy densities, thereby restricting its real world broad usage.

The primary ways to optimize the energy density of EDLCs are to increase the specific capacitance of the electrode materials and to widen the voltage window. Firstly, the specific capacitance of the electrode materials is closely related to their presented pore surface areas and distributions [4]. Secondly, the voltage window is usually limited by the electrolytes. What constitutes the electrode usually controls how the EDLC performs. In recent times, electrodes in EDLCs are commonly made of activated carbons [5-8]. Compared with conventional activated carbon precursors, such as charcoal and petroleum coke, these 
eco-friendly and renewable resources are more suitable. A recent widespread trend is to utilise bio-waste from agriculture (agro-wastes) as a source to manufacture activated carbon sustainably [9].

Recently, agro-wastes are broadly used to manufacture activated carbons sustainably. Agro-waste disposal has often been eliminated by disposing into landfills or by incinerating in open fields, resulting in severe air pollution. Using lignocellulosic agro-wastes for production of activated carbons has many benefits such as low-cost, high availability, renewability, and decreased costs of waste disposal. There are, however, some drawbacks to using agro-wastes to manufacture activated carbons that need to be eliminated. For instance, agro-wastes are extremely moist, heterogeneous, and highly contaminated.

Earlier investigations show that typical methods of agro-waste utilization are biological conversion, pyrolysis, and hydrothermal carbonization processes [10]. Hydrothermal carbonization (HTC) can be performed at relatively low temperatures $\left(180-250{ }^{\circ} \mathrm{C}\right) \mathrm{com}$ pared with the other conventional biomass processes such as pyrolysis. The HTC process is especially novel in the field of agro-waste utilization, which carbonizes wet biomass to circumvent energy required for the pre-drying process [11]. With its low energy requirements and no need for pre-drying biomass, HTC is a promising process for the preparation of carbon-based electrode materials for EDLCs [12,13].

Coconut shells are low-cost and renewable agro-wastes with an average composition of $25 \%$ hemicellulose, $36 \%$ cellulose, and $28 \%$ lignin, which makes them ideal candidates for activated carbon resources [14]. The coconut shell-based activated carbons have been widely used as adsorbents for water and air treatments [15,16], reduced graphenes [17], and electrodes $[18,19]$. As a result of a large surface area, a hierarchical porosity, as well as high conductivity, these activated carbons have been reported as better, compared with other agro-waste materials used as electrodes for supercapacitors [20-23].

In this study, a series of $\mathrm{KOH}$-treated, coconut shell-based carbons (CSCKs) were prepared for utilisation in electrodes for efficient and high energy EDLCs. In particular, CSCKs were obtained by hydrothermal carbonization, $\mathrm{KOH}$-activation, and carbonization of coconut shells. The ratio of $\mathrm{KOH}$ to hydrochar was varied to systematically study how it influences the texture and electrochemical behavior of the capacitor. To increase the voltage window, a carboxymethyl cellulose-lithium nitrate $\left(\mathrm{CMC}-\mathrm{LiNO}_{3}\right)$ electrolyte was applied. The solid state supercapacitor (SSC) device delivered an excellent specific energy of $48.9 \mathrm{Wh} \mathrm{kg}^{-1}$. The parameters involved to obtain the result were: Power density $=1.0 \mathrm{~kW} \mathrm{~kg}^{-1}$, current density $=2 \mathrm{~A} \mathrm{~g}^{-1}$, and a voltage window of $0-2.0 \mathrm{~V}$. Furthermore, the outstanding capacitance retention of $92 \%$ was obtained after a test cycle involving 5000 cycles. Overall, this study illustrates that the combination of the hydrothermal carbonization and chemical activation, with appropriate electrolytes, can produce low-cost supercapacitors sustainably for widespread application.

\section{Materials and Methods}

\subsection{Coconut Shell Carbons Preparation}

Coconut shells were obtained from the farmer's market in Tainan, Taiwan. The starting materials, washed with deionized water, were dried at $110{ }^{\circ} \mathrm{C}$ and $24 \mathrm{~h}$. Then, they were chopped into small pieces and ground into a powdered form. Afterwards, $6 \mathrm{~g}$ of coconut shell powder and $150 \mathrm{~mL}$ of distilled water were placed into a $250 \mathrm{~mL}$ Teflon-lined, stainless-steel autoclave followed by hydrothermal carbonization. The autoclave was sealed and heated to $180{ }^{\circ} \mathrm{C}$ for $12 \mathrm{~h}$ at a heating rate of $5^{\circ} \mathrm{C} / \mathrm{min}$ and then cooled to ambient conditions. Synthesized hydrochars were dried at $90{ }^{\circ} \mathrm{C}$ overnight for $\mathrm{KOH}$ chemical activation. To determine the influence of $\mathrm{KOH}$ concentration, the dried hydrochars were impregnated at a ratio of hydrochar to $\mathrm{KOH}$ at $1: 1,1: 2$, and $1: 3(w / w)$, while treating with $\mathrm{KOH}$. Forty milliliters of deionized water was used to disperse the mixture, while stirring continuously at $90^{\circ} \mathrm{C}$, lasting for $2 \mathrm{~h}$. Next, the samples were dried at $110{ }^{\circ} \mathrm{C}$, lasting for $24 \mathrm{~h}$. Subsequently, the carbonization procedure for all $\mathrm{KOH}$ treated samples was carried out under $\mathrm{N}_{2}$ flow at $800{ }^{\circ} \mathrm{C}$ at $5^{\circ} \mathrm{C} / \mathrm{min}$, lasting for $4 \mathrm{~h}$. After that, cooling was carried 
out to ambient conditions and the samples were cleaned using $0.2 \mathrm{M} \mathrm{HCl}$. The cleaning step is terminated when the $\mathrm{pH}$ of the cleaning water reached 6-7. Lastly, the synthesized coconut shell carbon (CSC) was dried in a vacuum at $80^{\circ} \mathrm{C}$ for over $12 \mathrm{~h}$ and the dried materials were labelled CSCK1, CSCK2, and CSCK3, according to their respective $\mathrm{KOH}$ concentrations. For comparison, a hydrothermal carbonization without $\mathrm{KOH}$ chemical activation of the raw coconut shells was carried out and named as CSC.

\subsection{Material Characterizations}

SEM images were obtained using a JEOL, JSM-6700F instrument. Textural properties of the carbon samples were measured using a Micromeritics, ASAP 2020A. The BET surface areas of the samples were obtained via the adsorption branch at $P / P_{0}<0.3$. Pore volumes $\left(V_{t}\right)$ were determined through the quantity of adsorbed nitrogen with a relative pressure $\left(P / P_{0}\right)$ of 0.995 . The $\mathrm{t}$-plot method was used to ascertain the micropore volumes $\left(\mathrm{V}_{\text {micro }}\right)$. Using a slit-shaped pore model, the distribution of the pore sizes were ascertained through the non-local density functional theory.

\subsection{Electrochemical Tests}

Electrochemical measurements of symmetric supercapacitors were carried out using a two- and three-electrode arrangements. The former contains a counter electrode made of $\mathrm{Pt}$ foil, a saturated calomel reference, a nickel foam working electrode, and a $6.0 \mathrm{M} \mathrm{LiNO}_{3}$ electrolyte. The preparation procedure for the working electrode, CSC/Ni, was as follows: a $75 \mathrm{wt} \%$ CSC, a $5 \mathrm{wt} \% \mathrm{KS}-6$, a $15 \mathrm{wt} \%$ Super $\mathrm{P}$, and a $5 \mathrm{wt} \%$ polyvinylidene fluoride binder were highly dispersed in N-methyl-2-pyrrolidinone solvent under an ultrasonic, and then coated on the nickel foams $\left(3.0 \times 2.0 \mathrm{~cm}^{2}\right)$ [24]. The working electrodes contain approximately $1.8 \mathrm{mg} \mathrm{cm}^{-2}$ of active materials. A pair of similar CSCK/Ni electrodes, a polymer electrolyte $\mathrm{CMC}-\mathrm{LiNO}_{3}$, a piece of polypropylene as a separator and an anti-static $\mathrm{Al}$ foil as the package material were used to fabricate the symmetric supercapacitors. To prepare the polymer electrolyte, dissolve $1 \mathrm{~g}$ of CMC was dissolved in agitated deionized water at $45{ }^{\circ} \mathrm{C}$. Then, $2 \mathrm{~g}$ of $\mathrm{LiNO}_{3}$ was added and stired to obtain a viscous mixture [25].

Galvanostatic charge and discharge (GCD), cyclic voltammetry (CV), and electrochemical impedance spectroscopy (EIS) were carried out at room temperature $\left(-25^{\circ} \mathrm{C}\right)$ using a $6273 \mathrm{E}(\mathrm{CHI})$ electrochemical workstation. The frequency range used to measure the EIS was $10 \mathrm{mHz}-100 \mathrm{kHz}$, while the AC perturbation was $5 \mathrm{mV}$. The voltage window is from -1.0 to $0.0 \mathrm{~V}$ vs. SCE for the CSCK/Ni electrodes and thus $0-2.0 \mathrm{~V}$ for the symmetric CSCK/Ni/ /CSCK/Ni supercapacitors. A 580 Battery Test System (Scribner Associates, Inc.) was used to measure the cyclic stability of the symmetric supercapacitor, where the voltage window was $0-2.0 \mathrm{~V}$ at $2 \mathrm{~A} \cdot \mathrm{g}^{-1}$.

From the GCD curves, the specific capacitances $\left(\mathrm{Cm}, \mathrm{F}^{-1}\right)$ of the electrodes and symmetric supercapacitors were calculated using Equation (1):

$$
C_{m}=\frac{I \times \Delta t}{m \times V}
$$

where $I, \Delta t, m$, and $V$ are the discharging current (A), the discharging time (s), the mass of the electroactive materials or total active materials in the positive and negative electrodes $(\mathrm{g})$, and the voltage change $(\mathrm{V})$, respectively.

Specific energy densities $\left(E, \mathrm{Wh} \cdot \mathrm{kg}^{-1}\right)$ and specific power densities $\left(P, \mathrm{~W} \cdot \mathrm{kg}^{-1}\right)$ for the symmetric supercapacitors were acquired via Equations (2) and (3):

$$
\begin{gathered}
E=\frac{0.5 C V^{2}}{3.6} \\
P=\frac{3600 \times E}{t}
\end{gathered}
$$


where $C\left(\mathrm{~F} \mathrm{~g}^{-1}\right)$ is the specific capacitance, $V(\mathrm{~V})$ is the operating voltage window, and $t(\mathrm{~s})$ is the discharge time.

\section{Results}

\subsection{Structural and Textural Properties}

Microstructural properties of the carbon samples were characterised using SEM. Micrographs of CSC and CSCK1 - CSCK3 samples are shown in Figure 1. Significant differences between the surface morphology of CSC (HTC treated) and CSCKs (HTC plus KOH treated) were observed. As shown in Figure 1a, the surface of CSC was rough and with no pores available on the surface. During HTC, the amorphous hemicellulose, cellulose, and lignin are postulated to have undergone liquefaction. Following that, leaching might have occurred, causing the materials to vacate the coconut shells, resulting in the random plane volumes as shown. In contrast, the structure was severely destroyed by $\mathrm{KOH}$ with the formation of porous and tattered surfaces for CSCK1 - CSCK3 (Figure 1b-d). The surface of CSCK1 was composed of small conchoidal cavities. With the increase in $\mathrm{KOH}$ amount, a highly porous, three-dimensional network structure was observed for CSCK2, while CSCK3 was quite irregular and full of micrometer-scale large pores on the skeleton. In this case, a high $\mathrm{KOH}$ concentration might have caused the formation of pores by altering the structures of the samples.

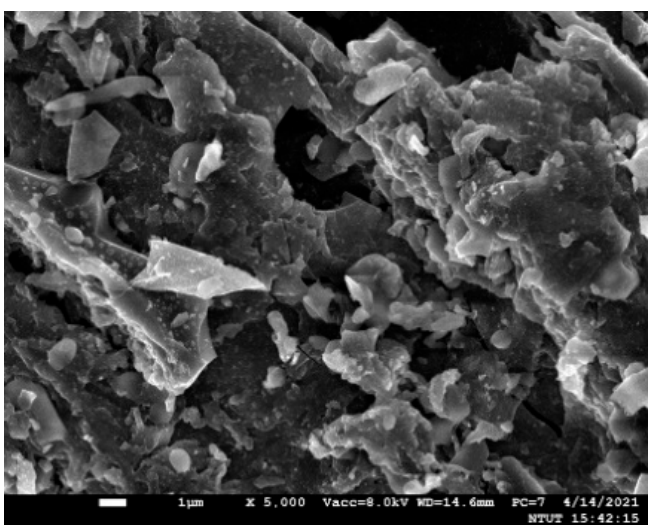

(a)

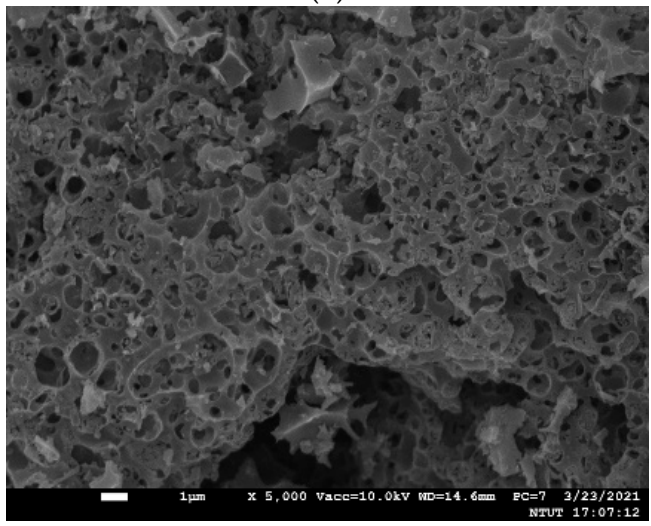

(c)

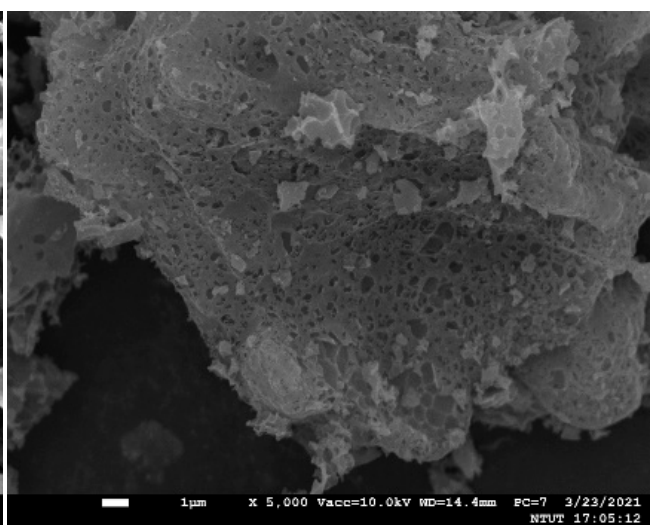

(b)

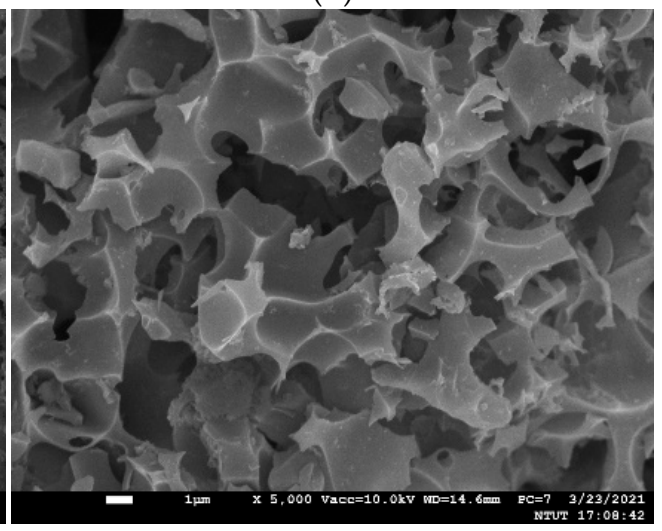

(d)

Figure 1. Micrographs obtained via SEM: (a) CSC, (b) CSCK1, (c) SCSK2, and (d) CSCK3.

The textural properties of the carbon electrodes could significantly affect the performance of EDLCs in terms of their supercapacitance. Nitrogen physisorption experiments carried out were used to investigate the carbon materials' porous nature, with the isotherm curves of all samples given in Figure 2a. The non-porous structure of CSC was further confirmed, since a horizontal line with low adsorbed volume was observed. After the $\mathrm{KOH}$ treatment, the isotherm curves of CSCKs were quite different from the CSC. As shown 
in Figure 2a, the CSCK range adsorbed a relatively high amount of $\mathrm{N}_{2}$ when $P / P_{0}<0.1$, indicating the abundance of micropores. Over the relative pressure of 0.8 , the multilayer adsorption of $\mathrm{N}_{2}$ occurred on activated carbon, resulting in the isotherms not reaching a horizontal plateau and indicating a tendency of the sample to have a macropore size distribution. The isotherms may be considered an intermediate between types I and II In accordance with the Brunauer-Deming-Deming-Teller (BDDB) classification [26], the isotherms appear to be a hybrid of Types I and II. This is due to the observable nitrogen absorption at low $P / P_{0}$, indicating the Type I isotherm, as well as nitrogen absorption at high $P / P_{0}$, indicating the Type II isotherm. In addition, unlike the other samples, the CSCK1 sample demonstrated a mixture of Type I and II isotherms, also showing hysteresis of the $\mathrm{H} 2$ type due to capillary condensation at $P / P_{0}=0.45-0.89$, signifying that it has high mesoporosity, and further suggesting that micro-, meso-, and macropores co-exist [27]. Such hierarchical micro/mesoporous texture for the CSCK samples was intuitively disclosed by their corresponding pore size distribution diagrams, depicted in Figure 2b. CSCK1 had a broad pore size of up to $50 \mathrm{~nm}$ and high ratio of mesopore volume. Using $\mathrm{KOH}$ in activating CSCK2 and CSCK3, the enlargement of their pores ensured, resulting in a drop in their mesoporous volume.

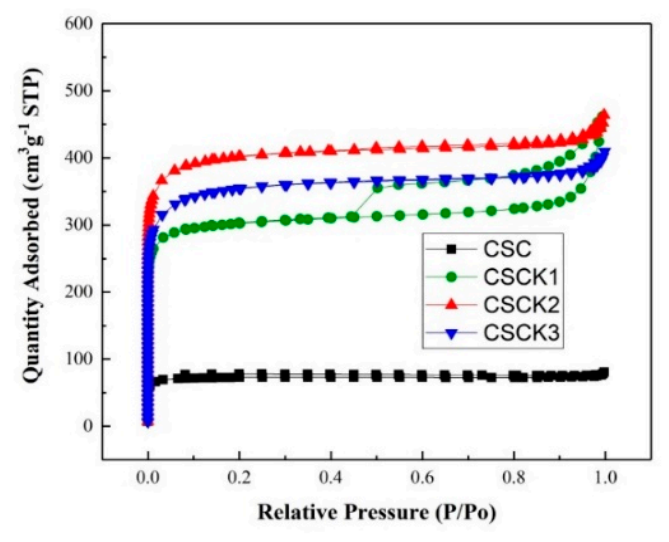

(a)

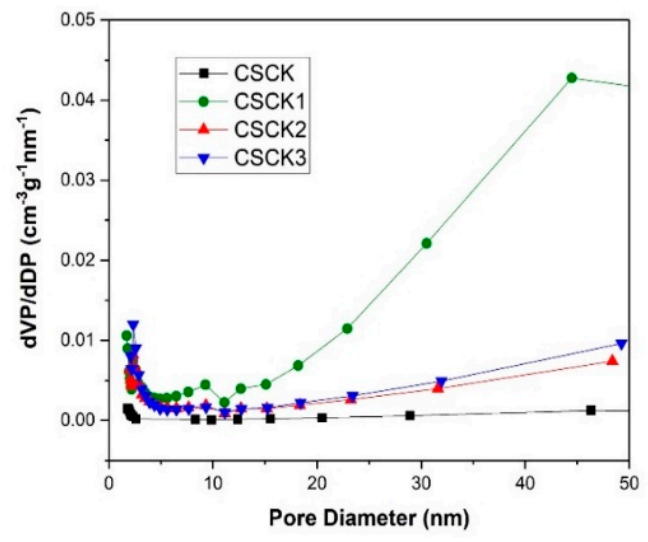

(b)

Figure 2. (a) $\mathrm{N}_{2}$ physisorption curves; and (b) pore size distribution of CSC and CSCKs.

Table 1 demonstrates the textural properties of the samples. The bulk CSC exhibits a low surface area $\left(287 \mathrm{~m}^{2} \mathrm{~g}^{-1}\right)$, whereas the porous CSCK samples exhibit much higher surface areas (1178-1567 $\left.\mathrm{m}^{2} / \mathrm{g}\right)$. Compared with CSC, there is a significant increase of $\mathrm{S}_{\mathrm{BET}}, \mathrm{S}_{\text {micro }}, \mathrm{V}_{\mathrm{t}}$, and $\mathrm{V}_{\text {micro }}$ of CSCK1 with the addition of $\mathrm{KOH}$. A further rise of $\mathrm{KOH}$ from the impregnation ratio of 1:2 to 1:3 would result in textural property that is worse than that of CSCK2. The result reveals that the amount of $\mathrm{KOH}$ has a significant effect on the textural quality of the sample. Based on the report of El-Hendawy [28], the $\mathrm{KOH}$ chemical activation leads to the formation of $\mathrm{K}_{2} \mathrm{CO}_{3}, \mathrm{CO}_{2}, \mathrm{CO}$, and $\mathrm{H}_{2}$ at a relatively low temperature $\left(\sim 400{ }^{\circ} \mathrm{C}\right)$ and $\mathrm{K}_{2} \mathrm{CO}_{3}$ contributes to the development of micropore structures. During the high temperatures between 700 and $800{ }^{\circ} \mathrm{C}$, the $\mathrm{K}_{2} \mathrm{CO}_{3}$ decomposes and results in the formation of the elemental $\mathrm{K}$, which intercalated to the carbon matrix and produced more wide pore structures. An excess amount of $\mathrm{KOH}$ results in the reduction of the BET surface area in CSCK3, which was a result of the existence of $\mathrm{K}_{2} \mathrm{CO}_{3}$. The formed pores were disrupted by the carbonates and brought about a decrease in surface area [29]. 
Table 1. Textrual properties of CSC and CSCKs.

\begin{tabular}{|c|c|c|c|c|c|}
\hline \multirow[b]{2}{*}{ Sample } & \multicolumn{5}{|c|}{ Textural Properties } \\
\hline & $\begin{array}{c}\mathrm{S}_{\mathrm{BET}}{ }^{1} \\
\left(\mathrm{~m}^{2} \mathrm{~g}^{-1}\right)\end{array}$ & $\begin{array}{c}S_{\text {micro }}{ }^{2} \\
\left(\mathrm{~m}^{2} \mathrm{~g}^{-1}\right)\end{array}$ & $\begin{array}{c}V_{t^{3}} \\
\left(\mathrm{~cm}^{3} \mathrm{~g}^{-1}\right)\end{array}$ & $\begin{array}{c}V_{\text {micro }}{ }^{4} \\
\left(\mathrm{~cm}^{3} \mathrm{~g}^{-1}\right)\end{array}$ & $\begin{array}{c}\mathrm{D}_{\text {ave }}{ }^{5} \\
\text { (nm) }\end{array}$ \\
\hline CSC & 287 & 271 & 0.11 & 0.10 & 1.60 \\
\hline CSCK1 & 1178 & 1020 & 0.68 & 0.40 & 2.32 \\
\hline CSCK2 & 1567 & 1343 & 0.69 & 0.53 & 1.77 \\
\hline CSCK3 & 1336 & 1079 & 0.61 & 0.43 & 1.82 \\
\hline
\end{tabular}

$\overline{{ }^{1} \text { Total BET specific surface area; }{ }^{2} \text { microporous surface area; }{ }^{3} \text { total pore volume; }{ }^{4} \text { microporous volume; }{ }^{5} \text { average }}$ pore size.

Raman spectroscopy was carried out to investigate how the structures of the materials evolved as $\mathrm{KOH}$ was added in different concentrations while the materials were being activated. Results for the spectroscopy are shown in Figure 3. Two apparent bands are detected approximately at the wavenumbers of 1350 and $1580 \mathrm{~cm}^{-1}$. At about $1350 \mathrm{~cm}^{-1}$, band ' $D$ ' appears as a result of the existence of imperfections or defects for the material. On the other hand, band ' $\mathrm{G}^{\prime}$ ca. $1580 \mathrm{~cm}^{-1}$ corresponds to the basal planes of graphene vibrating in the stretching mode. The ratios of $I_{D}$ to $I_{G}$ are representations of structural defects and disorders of the graphitic structures. In this study, the aforementioned ratio for the samples descend according to: CSCK3 (1.21) > CSCK2(1.00) > CSCK1(0.99) > CSC (0.95). The $\mathrm{I}_{\mathrm{D}} / \mathrm{I}_{\mathrm{G}}$ ratio for CSC was relatively low, which is attributed to its porous structure that are underdeveloped. Meanwhile, the aforesaid ratio for all CSCK samples was higher than 1, indicating the presence defect-rich structures in CSCKs. This indicated that $\mathrm{KOH}$ activation brings about considerable defect formation, resulting in the material's increased surface area and porosity (Table 1 ).

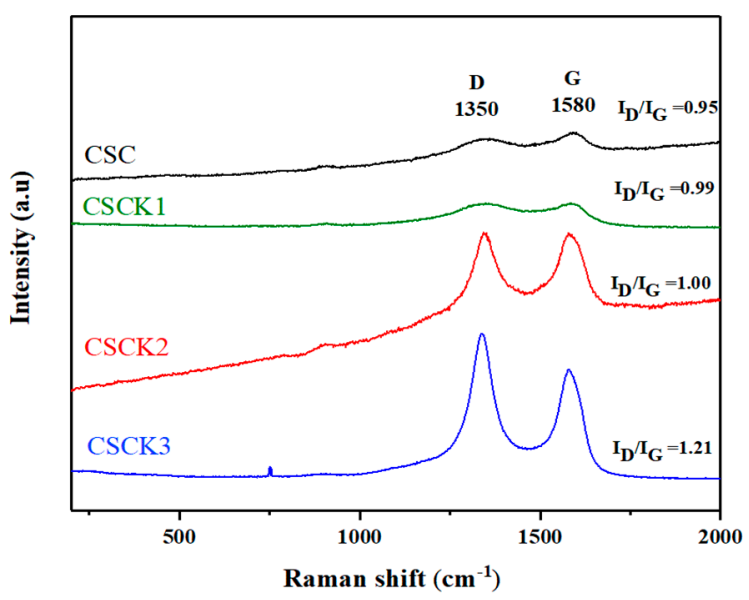

Figure 3. Raman spectra for the as-prepared CSC and CSCKs.

\subsection{Electrochemical Performance of the Electrode}

Previous investigations suggest that an increased BET surface area is beneficial for enhancement of electrochemical performance of EDLCs [4,30,31]. Since the surface area of CSC was much lower than that of CSCKs, the CSCKs were chosen as the CSCKs/Ni composites electrodes. Further experiments were carried out to ascertain the performance of the aforementioned composite when it is used for the electrodes of EDLCs. In particular, GCD tests, in the three-electrode configuration, were executed using the $\mathrm{LiNO}_{3}$ aqueous electrolyte at a concentration of $6 \mathrm{M}$. GCD curves of CSCK1, CSCK2, and CSCK3 are shown in Figure 4a. According to the figure, the curves exhibited negligible voltage drops and quasi-triangular patterns, signifying model capacitor behavior. The GCD curves were also used to obtain the specific capacitances of the material. The obtained values were 365, 387, and $292 \mathrm{~F} \mathrm{~g}^{-1}$, respective of CSCK1/Ni, CSCK2/Ni, and CSCK3/Ni. 


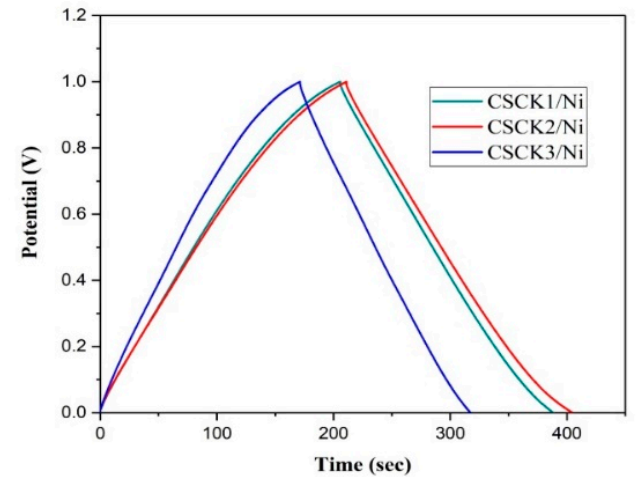

(a)

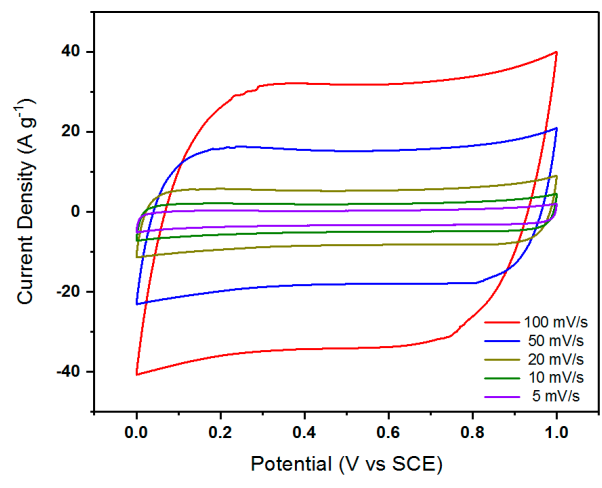

(c)

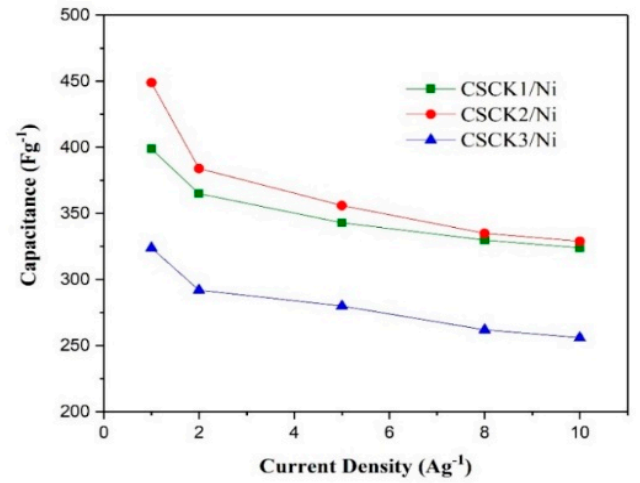

(b)

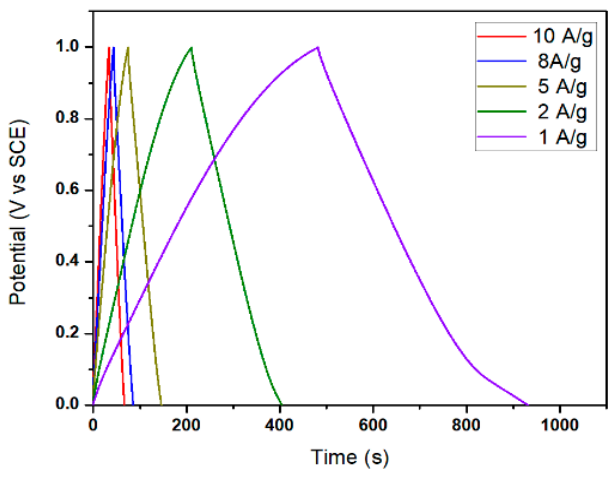

(d)

Figure 4. Electrochemical characteristics of CSCKs/Ni electrodes in $6 \mathrm{M} \mathrm{LiNO}_{3}$ aqueous electrolyte in a three-electrode system: (a) GCD curves at $2 \mathrm{~A} \mathrm{~g}^{-1}$ for CSCKs/Ni electrodes; (b) specific capacitances of CSCKs/Ni electrodes at various current densities; (c) CV curves of CSCK2/Ni electrode at various scan rates; and (d) GCD curves of CSCK2/Ni electrode at various current densities.

Figure $4 \mathrm{~b}$ demonstrates the CSCKs/Ni electrodes and their rate capabilities. Among them, CSCK2/Ni always displayed the largest specific capacitance when the current density was $1-10 \mathrm{~A} \mathrm{~g}^{-1}$, owing to its pore structure that is aptly hierarchical, thus advantageous in improving the ion diffusivity and charge transfer. At the capacitance $=449 \mathrm{~F} \mathrm{~g}^{-1}$, with a current density of $1 \mathrm{~A} \mathrm{~g}^{-1}$, the capacitance registered by CSCK2/Ni remained to be as $329 \mathrm{~F} \mathrm{~g}^{-1}$ at $10 \mathrm{~A} \mathrm{~g} \mathrm{~g}^{-1}$, indicating a decent rate capability. Therefore, a series of $\mathrm{CV}$ and GCD measurements of the CSCK2/Ni electrode were further investigated. As exhibited in Figure $4 a, c, d$, a quasi-rectangular shape was still retained for the graphs when the scanning rate was $5-100 \mathrm{mV} \mathrm{s}^{-1}$. In addition, all the GCD curves were nearly isosceles, with a minimal deviation from its linear shape, demonstrating the ideal supercapacitive behaviors. In this case, the CSCK2/Ni electrode, with a $\mathrm{KOH}$ ratio of 1:2, was found to be optimum, as the sample had the best-performing specific capacitance.

It is suggested that the pores with hierarchical properties in CSCK2/Ni enabled it to have an outstanding electrochemical performance. Demonstrating microporosity with pores $>0.40 \mathrm{~nm}$ in size, the material allows the easy penetration of ions from the $\mathrm{LiNO}_{3}$ electrolyte. To illustrate, $\mathrm{Li}^{+}$ions have diameters of $0.38 \mathrm{~nm}$, while $\mathrm{NO}_{3}{ }^{-}$have diameters of $0.34 \mathrm{~nm}$ [32]. Furthermore, CSCK2 presented an enhanced specific surface area, highest microporosity (microporous surface area and microporous volume), and optimal mesoporosity. These porous properties in turn allow the material to exhibit highly effective surface areas, which enhances ion diffusivity, ultimately greatly improving material capacitance. Several studies have suggested that the presence of optimal mesopores (usually $2 \mathrm{~nm}-8 \mathrm{~nm}$ ) in the EDLC are crucial to facilitate accelerated ion diffusivity, which increases the power density of the material [33-36]. 


\subsection{Evaluation of Symmetric Supercapacitor Electrochemical Performance}

Pertaining to the results from evaluating a single electrode, a pair of CSCK2/Ni electrodes were utilised to construct a SSC device - CSCK2/Ni//CSCK2/Ni. The device was present in a solid-state $\mathrm{CMC}-\mathrm{LiNO}_{3}$ gel electrolyte. $\mathrm{CV}$ curves obtained for the device are exhibited in Figure 5a. As envisioned, the shapes of the curves are close to rectangular, without obvious distortions. In addition, at increasing scan rates, the shape of the curves remained unchanged. This finding denotes that the device exhibits high rates of charge and discharge, as well as being less resistant to an equivalent series. On the other hand, Figure $5 b$ shows results of GCD tests at varied current densities. According to the figure, it can be seen that the curves exhibited good symmetry during charge and discharge, which signifies a model EDLC behaviour for the charge and discharge procedure. Next, Figure $5 c$ demonstrates how the applied current density affects the capacitance of the device. Taking into account the entire mass of active materials present in the electrodes, the mass loading was approximately $3.8 \mathrm{mg} \mathrm{cm}^{-2}$. Capacitance retention was up to $89.7 \%$ when $10 \mathrm{~A} \mathrm{~g}^{-1}$ was applied, denoting that it possesses a prominent rate capability. Next, Figure $5 \mathrm{~d}$ depicts the life-cycle study executed for the SS, appraised using a galvanostatic time-extended test cycle, with tested parameters of $2 \mathrm{~A} \mathrm{~g}^{-1}$ and $0-2.0 \mathrm{~V}$, for the current density and voltage window, respectively. After a charge and discharge cycle of 5000 rounds, the evaluation showed that the SSC also possessed $92 \%$ capacitance retention, indicating its excellent electrochemical durability. Furthermore, to study the variation in conductivity, charge-transfer properties, and diffusion properties after the cycling test, an EIS test was applied. Figure 5e presents the EIS measurements before and after the charge/discharge for 5000 cycles. At the region of high-frequency, intercepting the $x$-axis is the electrolyte resistance, substrate intrinsic resistance, and contact resistance $(R s)$. From the inset of Figure 5 e, the respective estimated $R s$ values were 1.33 and $1.26 \Omega$ for the after and before stability test. For the area of medium-high frequencies, the resistance of charge transfer $\left(R_{c t}\right)$ separating the electrode and electrolyte is represented by the semicircle diameter. As shown, the semicircles are insignificant, thus signifying that the faradaic charge transfer resistance is low. Whereas for the area of low-frequency, the Warburg resistance $\left(W_{s}\right)$ parameter is defined by the straight line of the graph. This parameter represents the resistance arising from ion diffusion or transport when it travels across the surface of the electrode from the electrolyte. The Warburg lines were steep, approximately $45^{\circ}$, before and after the charge/discharge for 5000 cycles and they were roughly overlapped, reflecting that the device contained electrolytic ions possessing low resistance to diffusion. Based on the EIS measurements, it once again confirms that the device is extremely stable.

In this study, power densities $(P)$ and energy densities $(E)$ of the SSC device in this study were acquired in accordance with Equations (2) and (3). The values were used to plot the Ragone plot, as seen in Figure $5 \mathrm{f}$. According to the graph, at the voltage window of $2 \mathrm{~V}$, a value of $48.9 \mathrm{Wh} \mathrm{kg}^{-1}$ was registered as the energy density, when the power density was $1 \mathrm{~kW} \mathrm{~kg}^{-1}$. Moreover, the exceptional capabilities of the device are observed when a high power density of $10 \mathrm{~kW} \mathrm{~kg}^{-1}$ was applied, in which $44.0 \mathrm{Wh} \mathrm{kg}^{-1}$ was still registered as the energy density, showing a minimal drop, which is superior to those of reported coconut shell-based supercapacitors such as CS-800-0.12-60 with 38.5 Wh kg-1 [36], AC4/ / AC4 with $35.2 \mathrm{Wh} \mathrm{kg}^{-1}$ [37], CS with $46.9 \mathrm{Wh} \mathrm{kg}^{-1}$ [38], and CH with $30.0 \mathrm{Wh} \mathrm{kg}^{-1}$ [39] In this study, the remarkable performance shown by CSCK2/Ni//CSCK2/Ni SS is due to the integration of improved surface area as well as apt pore distribution to the device. In addition, the proper selection of electrolyte allowed the charge to accumulate efficiently due to the presence of rich sites, while improving ion transportation and extending the operating voltage. 


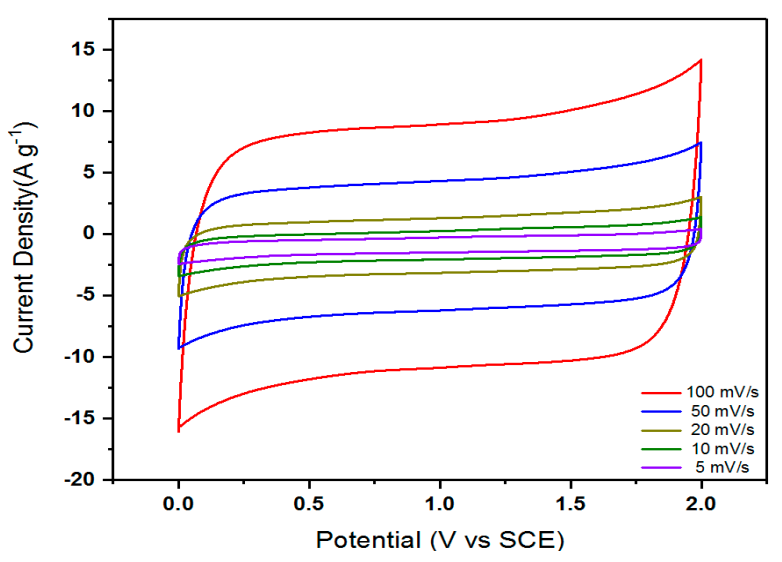

(a)

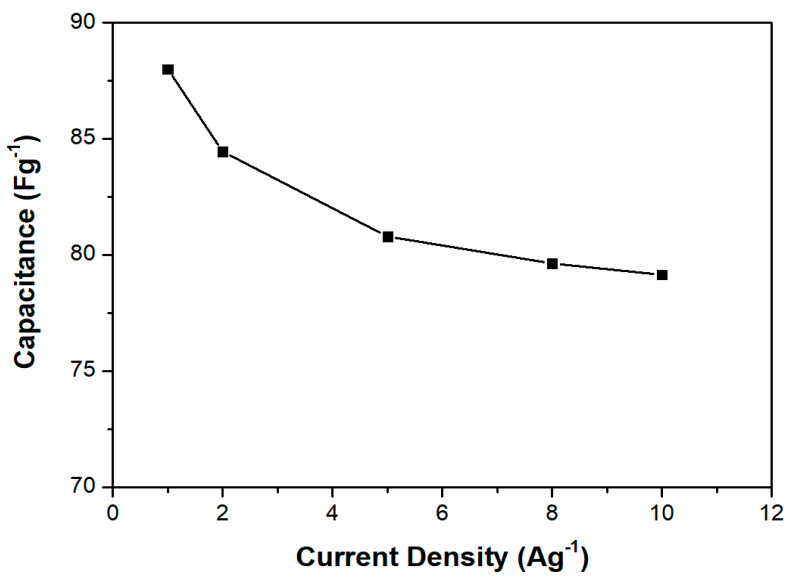

(c)

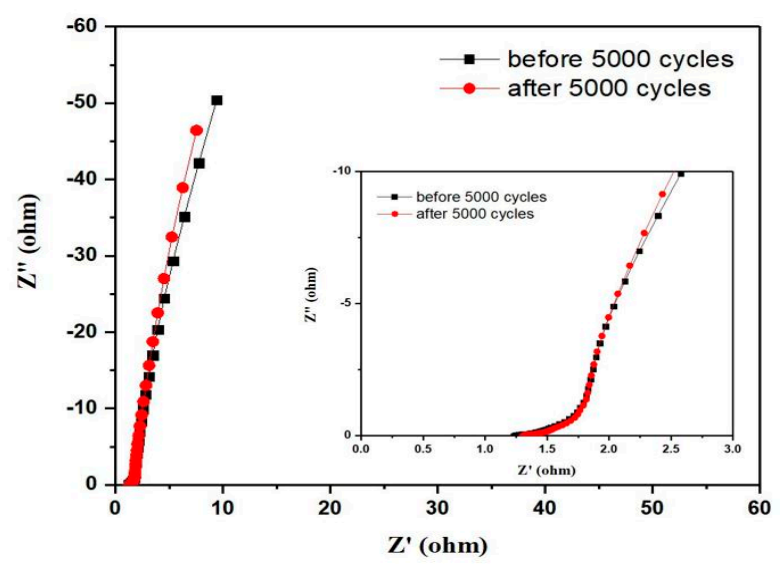

(e)

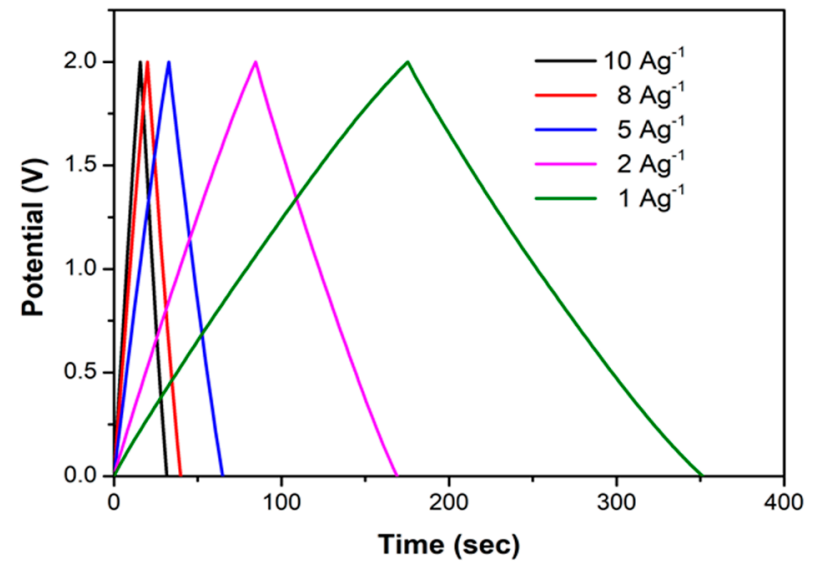

(b)

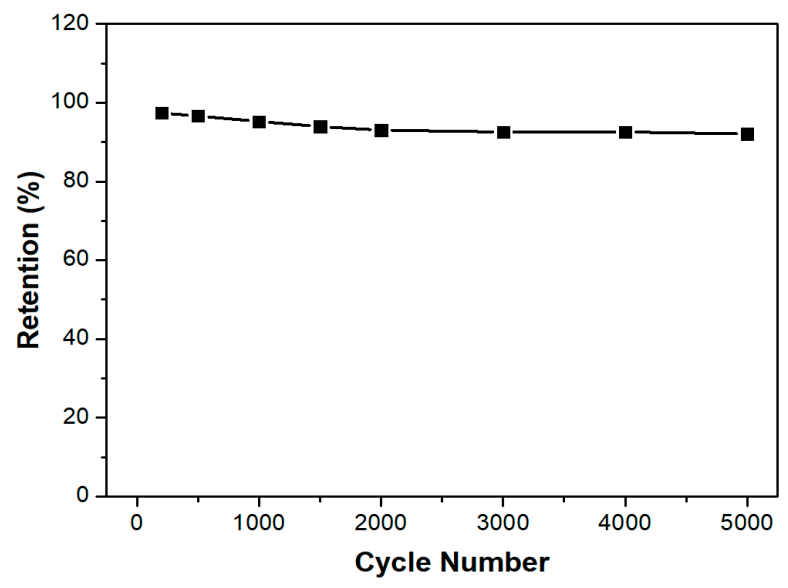

(d)

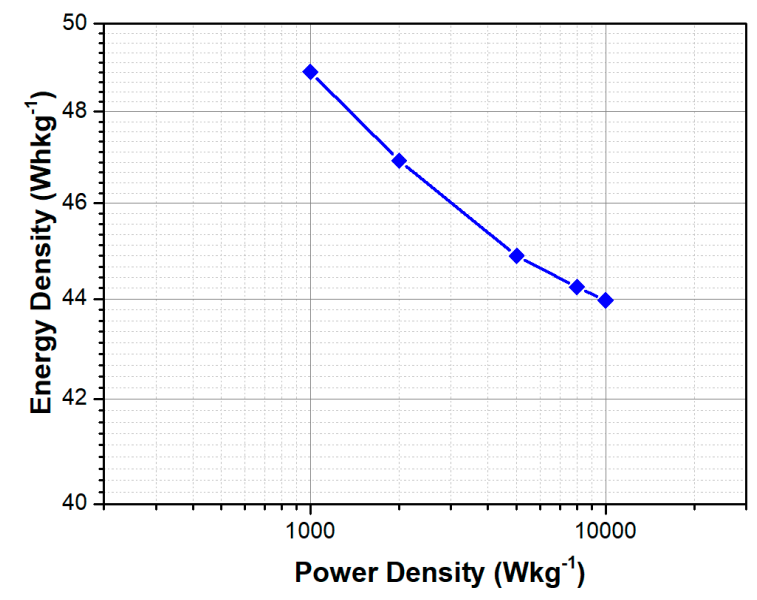

(f)

Figure 5. Electrochemical characteristics of a single as-prepared symmetric supercapacitor device of CSCK2/Ni//CSCK2/Ni: (a) CV curves at different sweep rates and a voltage window of 2 V; (b) GCD curves at

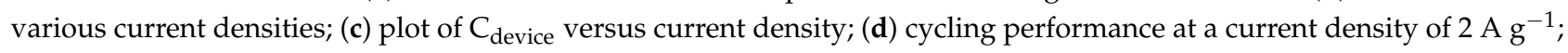
(e) Nyquist plots obtained for 5000 cycles; and (f) Ragone plot acquired for the device.

\section{Conclusions}

CSCKs were synthesized using coconut shells via the hydrothermal method, after activating with $\mathrm{KOH}$ and carbonizing. The material synthesized showed an enhanced BET surface area and the presence of micro-, meso-, and macropores. It was shown that the ratio 
of the $\mathrm{KOH}$ to the hydrochar used during synthesis greatly affected the textural properties of the materials. In particular, the CSCK2/Ni electrode showed an enhanced capacitance, at $449 \mathrm{~F} \mathrm{~g}^{-1}$ for the current density of $1 \mathrm{~A} \mathrm{~g}^{-1}$, a result better compared to literature values for coconut shell-derived electrodes. These exceptional results are accredited to the material presenting an enhanced surface area and apt distribution in pore sizes. Furthermore, the CSCK2/Ni electrode with $\mathrm{CMC}-\mathrm{LiNO}_{3}$ as the gel electrolyte was shown to exhibit a remarkable energy density of $49.9 \mathrm{Wh} \mathrm{kg}^{-1}$ when the power density used was $1 \mathrm{~kW} \mathrm{~kg}^{-1}$, while operating at a high voltage window of $2.0 \mathrm{~V}$. In the stability test, the material also demonstrated high cyclability, with a $92 \%$ retention after 5000 cycles. In conclusion, the positive results from this present study have established the feasibility of employing a green synthesis technique to transform bio-waste to useful porous carbons, which can be employed as EDLCs due to their high BET surface areas and structural advantages in terms of porosity.

Author Contributions: Conceptualization and writing-original draft, K.-C.L.; writing-original draft and writing—review and editing, M.S.W.L.; investigation, Z.-Y.H.; writing-review and editing, S.C.; methodology, T.J.T.; supervision, C.-M.H. and G.-T.P.; funding and resources: C.-M.H. All authors have read and agreed to the published version of the manuscript.

Funding: This research was funded by the Green Energy Technology Research Center from The Featured Areas Research Center Program within the framework of the Higher Education Sprout Project.

Institutional Review Board Statement: Not applicable.

Informed Consent Statement: Not applicable.

Acknowledgments: We express our sincere gratitude towards the Green Energy and Environment Research Laboratories of Industrial Technology Research Institute in providing the Ni foams.

Conflicts of Interest: The authors declare no conflict of interest.

\section{References}

1. Li, Z.; Guo, D.; Liu, Y.; Wang, H.; Wang, L. Recent advances and challenges in biomass-derived porous carbon nanomaterials for supercapacitors. Chem. Eng. J. 2020, 397, 125418. [CrossRef]

2. Chen, T.; Hao, R.; Peng, H.; Dai, L. High-performance, stretchable, wire-shaped supercapacitors. Angew. Chem. Int. Ed. 2015, 54, 618-622. [CrossRef]

3. Sudhan, N.; Subramani, K.; Karnan, M.; Ilayaraja, N.; Sathish, M. Biomass-derived activated porous carbon from rice straw for a high-energy symmetric supercapacitor in aqueous and non-aqueous electrolytes. Energy Fuels 2017, 31, 977-985. [CrossRef]

4. Chung, H.-Y.; Pan, G.-T.; Hong, Z.-Y.; Hsu, C.-T.; Chong, S.; Yang, T.C.-K.; Huang, C.-M. Biomass-derived porous carbons derived from soybean residues for high performance solid state supercapacitors. Molecules 2020, 25, 4050. [CrossRef]

5. Simon, P.; Gogotsi, Y. Capacitive energy storage in nanostructured carbon-electrolyte systems. Acc. Chem. Res. 2013, 46, 1094-1103. [CrossRef]

6. Sarno, M.; Baldino, L.; Scudieri, C.; Cardea, S.; Reverchon, E. A one-step SC-CO $\mathrm{C}_{2}$ assisted technique to produce compact PVDF-HFP MoS2 supercapacitor device. J. Phys. Chem. Solids 2020, 136, 109132. [CrossRef]

7. Lach, J.; Wróbel, K.; Wróbel, J.; Czerwiński, A. Applications of Carbon in Rechargeable Electrochemical Power Sources: A Review. Energies 2021, 14, 2649. [CrossRef]

8. Sharma, K.; Arora, A.; Tripathi, S.K. Review of supercapacitors: Materials and devices. J. Energy Storage 2019, 21, 801-825.

9. Yahya, M.A.; Al-Qodah, Z.; Ngah, C.Z. Agricultural bio-waste materials as potential sustainable precursors used for activated carbon production: A review. Renew. Sustain. Energy Rev. 2015, 46, 218-235. [CrossRef]

10. Wang, T.; Zhai, Y.; Zhu, Y.; Li, C.; Zeng, G. A review of the hydrothermal carbonization of biomass waste for hydrochar formation: Process conditions, fundamentals, and physicochemical properties. Renew. Sustain. Energy Rev. 2018, 90, 223-247. [CrossRef]

11. Benavente, V.; Calabuig, E.; Fullana, A. Upgrading of moist agro-industrial wastes by hydrothermal carbonization. J. Anal. Appl. Pyrolysis 2015, 113, 89-98. [CrossRef]

12. Reza, M.T.; Andert, J.; Wirth, B.; Busch, D.; Pielert, J.; Lynam, J.G.; Mumme, J. Hydrothermal carbonization of biomass for energy and crop production. Appl. Bioenergy 2014, 1, 11-29. [CrossRef]

13. Jiang, X.; Shi, G.; Wang, G.; Mishra, P.; Liu, C.; Dong, Y.; Zhang, P.; Tian, H.; Liu, Y.; Wang, Z. A hydrothermal carbonization process for the preparation of activated carbons from hemp straw: An efficient electrode material for supercapacitor application. Ionics 2019, 25, 3299-3307. [CrossRef]

14. Dhyani, V.; Bhaskar, T. A comprehensive review on the pyrolysis of lignocellulosic biomass. Renew. Energy 2018, 129, 695-716. [CrossRef] 
15. Li, L.; Liu, S.; Liu, J. Surface modification of coconut shell based activated carbon for the improvement of hydrophobic VOC removal. J. Hazard. Mater. 2011, 192, 683-690. [CrossRef] [PubMed]

16. Song, C.; Wu, S.; Cheng, M.; Tao, P.; Shao, M.; Gao, G. Adsorption studies of coconut shell carbons prepared by KOH activation for removal of lead (II) from aqueous solutions. Sustainability 2014, 6, 86-98. [CrossRef]

17. Mas'udah, K.W.; Nugraha, I.M.A.; Abidin, S.; Mufid, A.; Astuti, F.; Darminto. Solution of reduced graphene oxide synthesized from coconut shells and its optical properties. AIP Conf. Proc. 2016, 1725, 020045. Available online: https://aip.scitation.org/doi/ abs/10.1063/1.4945499 (accessed on 4 June 2021).

18. Jain, A.; Tripathi, S. Effect of nano-filler on the performance of multiwalled carbon nanotubes based electrochemical double layer capacitors. J. Renew. Sustain. Energy 2014, 6, 013108. [CrossRef]

19. Taer, E.; Taslim, R.; Putri, A.; Apriwandi, A.; Agustino, A. Activated carbon electrode made from coconut husk waste for supercapacitor application. Int. J. Electrochem. Sci. 2018, 13, 12072-12084. [CrossRef]

20. Kuratani, K.; Okuno, K.; Iwaki, T.; Kato, M.; Takeichi, N.; Miyuki, T.; Awazu, T.; Majima, M.; Sakai, T. Converting rice husk activated carbon into active material for capacitor using three-dimensional porous current collector. J. Power Sources 2011, 196, 10788-10790. [CrossRef]

21. Xiong, W.; Liu, M.; Gan, L.; Lv, Y.; Li, Y.; Yang, L.; Xu, Z.; Hao, Z.; Liu, H.; Chen, L. A novel synthesis of mesoporous carbon microspheres for supercapacitor electrodes. J. Power Sources 2011, 196, 10461-10464. [CrossRef]

22. Jiang, Q.; Liu, D.; Liu, B.; Zhou, T.; Zhou, J. Blotting paper-derived activated porous carbon/reduced graphene oxide composite electrodes for supercapacitor applications. Molecules 2019, 24, 4625. [CrossRef]

23. Mensah-Darkwa, K.; Zequine, C.; Kahol, P.K.; Gupta, R.K. Supercapacitor energy storage device using biowastes: A sustainable approach to green energy. Sustainability 2019, 11, 414. [CrossRef]

24. Pan, G.-T.; Chong, S.; Yang, T.C.-K.; Huang, C.-M. Electrodeposited porous Mn1. 5Co1. 5O4/Ni composite electrodes for high-voltage asymmetric supercapacitors. Materials 2017, 10, 370. [CrossRef]

25. Erusappan, E.; Pan, G.-T.; Chung, H.-Y.; Chong, S.; Thiripuranthagan, S.; Yang, T.C.-K.; Huang, C.-M. Hierarchical nickel-cobalt oxide and glucose-based carbon electrodes for asymmetric supercapacitor with high energy density. J. Taiwan Inst. Chem. Eng. 2020, 112, 330-336. [CrossRef]

26. Hwang, N.; Barron, A.R. BET surface area analysis of nanoparticles. Connex. Proj. 2011, 1-11. Available online: http://cnx.org/ content/m38278/1.1/ (accessed on 4 June 2021).

27. Miao, Q.; Tang, Y.; Xu, J.; Liu, X.; Xiao, L.; Chen, Q. Activated carbon prepared from soybean straw for phenol adsorption. J. Taiwan Inst. Chem. Eng. 2013, 44, 458-465. [CrossRef]

28. El-Hendawy, A.-N.A. An insight into the $\mathrm{KOH}$ activation mechanism through the production of microporous activated carbon for the removal of $\mathrm{Pb}^{2+}$ cations. Appl. Surf. Sci. 2009, 255, 3723-3730. [CrossRef]

29. Wang, J.; Kaskel, S. KOH activation of carbon-based materials for energy storage. J. Mater. Chem. 2012, 22, 23710-23725. [CrossRef]

30. Karamanova, B.; Stoyanova, A.; Shipochka, M.; Veleva, S.; Stoyanova, R. Effect of Alkaline-Basic Electrolytes on the Capacitance Performance of Biomass-Derived Carbonaceous Materials. Materials 2020, 13, 2941. [CrossRef]

31. Charoensook, K.; Huang, C.-L.; Tai, H.-C.; Lanjapalli, V.V.K.; Chiang, L.-M.; Hosseini, S.; Lin, Y.-T.; Li, Y.-Y. Preparation of porous nitrogen-doped activated carbon derived from rice straw for high-performance supercapacitor application. J. Taiwan Inst. Chem. Eng. 2021, 120, 246-256. [CrossRef]

32. Israelachvili, J.N. Intermolecular and Surface Forces; Academic Press: Burlington, MA, USA, 2015.

33. Wei, X.; Jiang, X.; Wei, J.; Gao, S. Functional groups and pore size distribution do matter to hierarchically porous carbons as high-rate-performance supercapacitors. Chem. Mater. 2016, 28, 445-458. [CrossRef]

34. Rose, M.; Korenblit, Y.; Kockrick, E.; Borchardt, L.; Oschatz, M.; Kaskel, S.; Yushin, G. Hierarchical micro-and mesoporous carbide-derived carbon as a high-performance electrode material in supercapacitors. Small 2011, 7, 1108-1117. [CrossRef] [PubMed]

35. Li, Q.; Jiang, R.; Dou, Y.; Wu, Z.; Huang, T.; Feng, D.; Yang, J.; Yu, A.; Zhao, D. Synthesis of mesoporous carbon spheres with a hierarchical pore structure for the electrochemical double-layer capacitor. Carbon 2011, 49, 1248-1257. [CrossRef]

36. Mi, J.; Wang, X.-R.; Fan, R.-J.; Qu, W.-H.; Li, W.-C. Coconut-shell-based porous carbons with a tunable micro/mesopore ratio for high-performance supercapacitors. Energy Fuels 2012, 26, 5321-5329. [CrossRef]

37. Ashraf, C.M.; Anilkumar, K.; Jinisha, B.; Manoj, M.; Pradeep, V.; Jayalekshmi, S. Acid washed, steam activated, coconut shell derived carbon for high power supercapacitor applications. J. Electrochem. Soc. 2018, 165, A900. [CrossRef]

38. Omokafe, S.M.; Adeniyi, A.A.; Igbafen, E.O.; Oke, S.R.; Olubambi, P.A. Fabrication of Activated Carbon from Coconut Shells and its Electrochemical Properties for Supercapacitors. Int. J. Electrochem. Sci. 2020, 15, 10854-10865. [CrossRef]

39. Taer, E.; Naipospos, V.M.; Taslim, R. Activated Carbon Monolith Derived from Coconut Husk Fiber as Electrode Material for Supercapacitor Energy Storage. J. Phys. Conf. Ser. 2020, 1655, 012164. [CrossRef] 